\title{
Primate Erythrocyte-Immune Complex-clearing
}

\section{Mechanism}

\author{
J. B. Cornacoff, L. A. Hebert, W. L. Smead, M. E. Vanaman, \\ D. J. Birmingham, and F. J. Waxman, Departments of Medicine, Surgery, \\ Radiology, and Medical Microbiology and Immunology, The Ohio State \\ University, Columbus, Ohio 43210
}

\begin{abstract}
A BSTRACT Previous in vitro studies have shown that immune complexes (IC) that fix complement can bind to the $\mathrm{C} 3 \mathrm{~b}$ receptor on primate erythrocytes. The in vivo function of this erythrocyte receptor, however, is unknown. This study was undertaken to determine whether the binding of IC to erythrocytes in vivo might play a role in the removal of IC from the circulation. Baboons and rhesus monkeys were prepared with a catheter in the ascending aorta to infuse IC and in the abdominal aorta, renal, hepatic, and portal veins to monitor changes in binding and clearance of IC across kidney, liver, and spleen + gut, respectively. Autologous ${ }^{51} \mathrm{Cr}$-labeled erythrocytes were infused intravenously and allowed to equilibrate. Preformed IC $\left({ }^{125} \mathrm{I}\right.$-labeled bovine serum albumin [BSA] rabbit antiBSA) were then infused into the ascending aorta at a constant rate for $120 \mathrm{~s}$. Blood samples were drawn at frequent intervals for $30 \mathrm{~min}$ from all catheters below the IC injection site. Each blood sample was then centrifuged on percoll to separate IC bound to erythrocytes from IC in plasma or bound to buffy coat cells. This resulted in an "erythrocyte fraction" beneath the percoll that contained the IC bound to erythrocytes, and a "plasma/buffy coat fraction" above the percoll that contained the IC in plasma and IC bound to buffy coat cells. Analysis of these data showed that the majority of the IC infused into the circulation rapidly became bound to erythrocytes. However, by $5 \mathrm{~min}$ after beginning the IC infusion, most of this IC load had been removed from the erythrocytes as they traversed the liver. In contrast, IC on erythrocytes did not deposit in kidney. The IC-bearing erythrocytes themselves were not trapped or detained by any organ. IC in the plasma/buffy coat fraction of blood were removed from the circulation but at a relatively low
\end{abstract}

Address reprint requests to Dr. Hebert, Department of Medicine, The Ohio State University, Columbus, OH 43210.

Received for publication 3 March 1982 and in revised form 19 October 1982. rate and almost entirely by the liver. These findings suggest that primate erythrocytes intercept large complement-fixing IC in the circulation causing the IC to adhere to the erythrocyte until the IC-bearing erythrocyte traverses liver where the IC is deposited, and the erythrocyte is returned to the circulation. This primate erythrocyte-IC-clearing mechanism may be important in the protection against diseases mediated by deposition of circulating IC.

\section{INTRODUCTION}

Complement receptor type $1\left(\mathrm{CR}_{1}\right),{ }^{1}$ which has receptor specificity for the $\mathrm{C} 3 \mathrm{~b}$ and $\mathrm{C} 4 \mathrm{~b}$ components of the complement system, is present on the surface of human and other primate erythrocytes $(1,2)$. The average number of $\mathbf{C R}_{1}$ receptors per erythrocyte is small (mean $<2,000 /$ cell) compared with that of circulating $B$ lymphocytes, monocytes, and neutrophils where the average number of $\mathrm{CR}_{1}$ receptors per cell ranges from 21,000 to 148,000 (1-3). However, because circulating erythrocytes greatly outnumber circulating leukocytes, the vast majority of all $\mathbf{C R}_{1}$ receptors present in the circulation of humans and other primates is located on the erythrocyte (4).

The $C_{1}$ receptors on lymphocytes, macrophages, and neutrophils have been shown to play important roles in immune regulation and in phagocytosis $(5,6)$. By contrast, to date no important in vivo function has been found for the vast number of $\mathbf{C R}_{1}$ receptors in the circulating erythrocyte pool. However, it is well established that, in vitro, immune complexes (IC) that fix complement can bind to primate erythrocytes via the $\mathrm{CR}_{1}$ receptor $(6-9)$. It seems possible that the erythrocyte, by virtue of its ability to bind IC and its ubiq-

\footnotetext{
${ }^{1}$ Abbreviations used in this paper: BSA, bovine serum albumin; $\mathrm{CR}_{1}$, complement receptor type 1 ; IC, immune complexes.
} 
uity in the vascular space, could play a role in the removal of circulating IC from the blood stream. The present study was undertaken to test that hypothesis. The results indicate that primate erythrocytes participate in a rapid and efficient mechanism for removal of large complement-fixing IC from the circulation.

\section{METHODS}

\section{Preparation of IC}

Crystallized bovine serum albumin (BSA, Sigma Chemical Co., St. Louis, MO) was labeled with ${ }^{125}$ I as previously described (10). Labeling efficiency was $\sim 70 \%$ and specific activity ranged from 20 to $30 \mu \mathrm{Ci} / \mathrm{mg}$. Anti-BSA antibody was produced by immunizing New Zealand rabbits, as previously described (10). The serum antibody concentration was measured by the quantitative precipitin method. IC were formed by combining at equivalence heat-inactivated rabbit antiserum with ${ }^{125} \mathrm{I}$-labeled BSA ( ${ }^{125} \mathrm{I}-\mathrm{BSA}$ ), incubating for $1 \mathrm{~h}$ at $37^{\circ} \mathrm{C}$ and then at $4^{\circ} \mathrm{C}$ for $48 \mathrm{~h}$. The resulting precipitate was centrifuged $(1,200 \mathrm{~g}$ for $10 \mathrm{~min})$, washed, and then incubated with $0.01 \mathrm{M}$ phosphate-buffered saline (PBS, pH 7.2) to which five times excess of unlabeled BSA was added. The solution was agitated for $4 \mathrm{~h}$ at $37^{\circ} \mathrm{C}$, centrifuged $(100$ $g$ for $20 \mathrm{~min}$ ), and the precipitate discarded. Approximately $5-30 \%$ of the precipitate was solubilized by this method, as assessed by loss of ${ }^{125} \mathrm{I}$ counts per minute from the precipitate. All IC preparations were made 24-48 h before use and were stored at $4^{\circ} \mathrm{C}$. This IC preparation was chosen for study because it showed much higher levels of complement-dependent binding to human and simian erythrocytes compared with IC preparations subjected to centrifugation at 500 or $1,000 g(8)$.

To assess the extent to which the ${ }^{125}$ I-BSA was incorporated into IC, $1 \mathrm{ml}$ of $20 \%$ polyethylene glycol 6000 (PEG) was added to $10 \mu \mathrm{l}$ of IC solution. This concentration of PEG precipitates $>90 \%$ of the ${ }^{125}$ I-BSA that is incorporated into IC, but $<10 \%$ of the ${ }^{125}$ I-labeled BSA that is not incorporated into IC (12). By this procedure $\sim 90 \%$ of ${ }^{125}$ I-BSA was in the form of IC.

\section{Surgical preparation}

Seven primates (three female rhesus monkeys, one male, and three female baboons) were used. The animals weighed 5.4-30.2 kg. Anesthesia was induced by intramuscular administration of Ketamine and atropine. An endotracheal tube was then inserted and anesthesia maintained with inhalation of halothane and nitrous oxide. Electrocardiographic monitoring was maintained throughout the experiment. Intravenous Ringer's lactate was infused continuously at $1-3 \mathrm{ml} / \mathrm{min}$, depending on body size. Under sterile conditions (four experiments) or nonsterile conditions (three experiments) the common femoral artery and vein of both lower extremities were isolated to facilitate angiographic catheter placement. An upper midline abdominal incision was then made to provide exposure of the portal vein in the porta hepatis. A No. 5 French polyethylene feeding tube was then placed in the portal vein through a stab incision and stabilized with a 6.0 polypropylene suture. The animal was then transferred to the fluoroscopy room where an angiographic catheter ( 5 or 6 French with torque control) was placed, under fluoroscopic guidance and with the aid of infusion of contrast media, into each of the following locations: the ascending aorta just above the aortic valve, the abdom- inal aorta at the level of the renal arteries, the renal vein (right or left), and a right hepatic vein. The aortic arch catheter was used for periodic measurement of arterial blood pressure, for infusion of the IC and, in three experiments, for infusion of ${ }^{85} \mathrm{Sr}$-labeled microspheres $(15 \pm 0.8 \mu \mathrm{m}, 3 \mathrm{M}$ Company, St Paul, MN) to assess tissue blood flow. The remaining catheters made it possible to monitor changes in blood composition across kidney (arterial vs. renal vein blood), across liver (arterial + portal vein vs. hepatic vein blood) and across the portal circulation (arterial vs. portal vein blood). The portal vein provides the venous drainage of the spleen, stomach, small bowel, large bowel, and pancreas. Hereafter, these organs will be simply referred to as spleen + gut.

\section{Experimental protocol}

Animals were infused with autologous ${ }^{51} \mathrm{Cr}$-labeled erythrocytes as follows: $10-20 \mathrm{ml}$ of blood were removed, the erythrocytes isolated, washed in Hanks' balanced salt solution, labeled with $20-40 \mu \mathrm{Ci}$ of ${ }^{51} \mathrm{Cr}(10)$, washed, infused, and allowed to circulate for a minimum of $20 \mathrm{~min}$. 10-20 $\mathrm{ml}$ of IC $(0.3-2.2 \mathrm{mg})$ were then infused at a steady rate with a hand-held syringe over $120 \mathrm{~s}$. Blood samples $(\sim 1 \mathrm{ml})$ were drawn simultaneously from the catheters in the abdominal aorta, hepatic, portal, and renal veins into tuberculin syringes that contained $10 \mathrm{U}$ of heparin. The blood samples were drawn starting at time 0 , at 20 -s intervals until $120 \mathrm{~s}$ had elapsed, and then at 3, 4, 5, 15, and $30 \mathrm{~min}$. Each blood sample was transferred to an iced tube immediately after it was drawn. The tubes remained iced until processed as described below. All processing of these blood samples was done within $2 \mathrm{~h}$ of completing the experiment. Arterial blood pressure was monitored immediately before starting the IC infusion and at 5 and $30 \mathrm{~min}$ into the experiment. After obtaining the last $(30 \mathrm{~min})$ blood specimen, the position of the catheters in the aortic arch, renal vein, and hepatic vein was reassessed angiographically. In no experiment did catheter displacement occur. In the four experiments performed under sterile surgical conditions, the arteriotomy and venotomy incisions were then sutured and the animals allowed to recover from the general anesthesia. In the three experiments performed under nonsterile conditions, 1-2 $\mu \mathrm{Ci}$ of ${ }^{85} \mathrm{Sr}$-labeled micropheres were infused into the aortic arch catheter and, after 2-3 min had elapsed, the animals were sacrificed by infusion of pentobarbital. To determine the content of each isotope in each organ, an aliquot $(\bar{\Sigma} 10 \%)$ was taken from liver, kidney, spleen, stomach, large bowel, small bowel, pancreas, and lung and the isotope counts per minute determined as described previously (11).

\section{Processing of blood samples}

Each blood sample obtained during the experiment was immediately transferred to an iced tube. Under these conditions, additional binding of IC to erythrocytes ceases, and erythrocyte-bound IC do not dissociate (see below). Thus, icing the blood samples helps stabilize the binding of IC to erythrocytes at the same level as that present in vivo.

To determine the extent to which the IC had become bound to erythrocytes, in vivo, it was necessary to devise a technique for separating IC bound to erythrocytes from IC not bound to erythrocytes. This could not be done simply by centrifugation of the whole blood specimens because the centrifugation force necessary to efficiently separate erythrocytes from leukocytes results in the downward migration of some of the IC population with the erythrocytes, even though the IC are not bound to the erythrocyte. To obviate 
this problem, the following technique was devised: whole blood $(0.5 \mathrm{ml})$ was placed on top of $3 \mathrm{ml}$ of iced percoll (Sigma Chemical Co.) diluted in $0.15 \mathrm{M} \mathrm{NaCl}$ to a density of $1.100 \mathrm{~g} / \mathrm{ml}$. This preparation was then centrifuged at 350 $g$ for $15 \mathrm{~min}$. Under these conditions, $>97 \%$ of the erythrocytes and IC bound to erythrocytes migrate to the bottom of the centrifuge tube and $>95 \%$ of free ${ }^{125} \mathrm{I}-\mathrm{BSA}$ and IC bound to the buffy coat cells or free in the plasma, remain at the top of the percoll. The separation of buffy coat cells from erythrocytes was highly efficient as shown by the fact that, after centrifugation of whole blood on percoll, leukocytes were undetectable in the erythrocyte fraction by Coulter counter techniques (Coulter Electronics Inc., Hialeah, FL). In addition, microscopic examination of Wright-stained specimens of the erythrocyte fraction revealed no evidence of leukocytes or platelets. When IC alone were placed on top of the percoll (with or without fresh serum) and centrifuged as described above, $<4 \%$ of the IC preparation migrated to the bottom of the tube during centrifugation (8). The protocol for these experiments is described below.

\section{In vitro binding of IC to erythrocytes}

Equal volumes of IC (prepared as described above), fresh undiluted baboon serum, and packed baboon erythrocytes (washed three times in PBS; buffy coat cells removed following each wash) were added together in duplicate iced tubes $(12 \times 75 \mathrm{~mm})$. The contents were mixed and incubated at $37^{\circ} \mathrm{C}$ for $10 \mathrm{~min}$ in a shaker water bath. After incubation the reaction mixtures were removed, placed on iced percoll and centrifuged at $350 \mathrm{~g}$ for $15 \mathrm{~min}$ at $4^{\circ} \mathrm{C}$. After centrifugation, the unbound IC (remaining on top of the percoll) were removed along with the percoll, leaving the erythrocytes with bound IC as a pellet at the bottom. The ${ }^{125}$ I counts per minute of both fractions were measured in a gamma scintillation spectrometer (model 5230, Packard Instrument Co., Inc., Downers Grove, IL). The percent of IC bound to erythrocytes was calculated as follows: \% bound $=\left({ }^{125} \mathrm{I} \mathrm{cpm}\right.$ erythrocyte fraction) $/ 0.9\left({ }^{125} \mathrm{I} \mathrm{cpm}\right.$ erythrocyte fraction + percoll fraction) $\times 100$, where $0.9=$ fraction of ${ }^{125} \mathrm{I} \mathrm{cpm}$ that represent IC. Reaction mixtures containing equal volumes of IC, heat-inactivated serum, and packed baboon erythrocytes were included during the $37^{\circ} \mathrm{C}$ incubation period as negative controls.

To assess whether the immediate cooling to $4^{\circ} \mathrm{C}$ of the primate blood samples stabilize the IC binding to erythrocytes that has already occurred but prevents further IC binding to erythrocytes, the following in vitro experiments were performed. IC + erythrocytes + fresh plasma were incubated at $37^{\circ} \mathrm{C}$ for $10 \mathrm{~min}$ and then immediately transferred to a $4^{\circ} \mathrm{C}$ bath. Another incubate, consisting of IC + erythrocytes + fresh plasma, was incubated at $4^{\circ} \mathrm{C}$ continuously. Aliquots of each reaction mixture were removed periodically to measure binding of IC to erythrocytes, as described above. The results of a representative experiment are shown in Fig 1. As can be seen, at $4^{\circ} \mathrm{C}$, IC binding to erythrocytes does not occur but IC already bound to erythrocytes do not dissociate. Thus, cooling the blood samples to $4^{\circ} \mathrm{C}$ maintains the level of IC binding to erythrocytes at the same levels as those present in vivo.

\section{Analysis of IC size by isokinetic sucrose gradients}

Isokinetic sucrose gradients were constructed as described by Johns and Stanworth (13). Briefly, exponential gradients were formed of $15-24.25 \%$ sucrose (wt/wt, isokinetic at $20^{\circ} \mathrm{C}$ ) using a constant volume mixing chamber (kindly provided by Dr. Ronald Taylor, Department of Biochemistry, University of Virginia School of Medicine). The gradients (total gradient volume $=4.8 \mathrm{ml}$ ) were placed in a temperature-regulated ultracentrifuge (model L8-55, Beckman Instruments, Inc., Palo Alto, CA) and equilibrated at $20^{\circ} \mathrm{C}$. To determine the population of IC that bind to baboon erythrocytes the following three reaction mixtures were prepared in duplicate: (a) fresh serum + IC + erythrocytes; $(b)$ fresh serum + IC + PBS; and (c) heat-inactivated serum + IC + erythrocytes. After $10 \mathrm{~min}$ at $37^{\circ} \mathrm{C}$, each reaction mixture was placed on percoll and centrifuged at $350 \mathrm{~g}$ for $15 \mathrm{~min}$. After centrifugation, the material above the percoll was removed, the ${ }^{125} I$ counts per minute determined and then placed on the 15-24.25\% isokinetic sucrose gradients. The gradients were centrifuged at $1,500 \mathrm{rpm}$ for $30 \mathrm{~min}\left(w^{2} t\right.$ $\left.=4.39 \times 10^{7} \mathrm{rad}^{2} / \mathrm{s}\right)$ at $20^{\circ} \mathrm{C}$. The gradients were then removed and fractionated via bottom displacement with $35 \%$ sucrose. $0.2-\mathrm{ml}$ fractions were collected (total of 25 fractions) and ${ }^{125} \mathrm{I}$ counts per minute determined. The ${ }^{125} \mathrm{I}$ counts per minute of each fraction was then plotted against the sedimentation coefficient $\left(S_{20}, w\right)$ corresponding to each sucrose fraction.

\section{Calculations}

Peak in vivo binding of IC to erythrocytes. This was taken as $\mathrm{IC}_{e} /\left(0.9 \times \mathrm{IC}_{t}\right) \times 100$, where $\mathrm{IC}_{e}={ }^{125} \mathrm{I}$ counts per minute in the erythrocyte fraction at the time of the peak $I_{\mathrm{t}_{\mathrm{t}}} ; \mathrm{IC}_{\mathrm{t}}=$ the total ${ }^{125} \mathrm{I}$ counts per minute in the blood sample; $0.9=$ fraction of total ${ }^{125} \mathrm{I}$ counts per minute in blood that represents IC.

Fractional removal of IC from erythrocytes traversing liver or kidney or spleen + gut. This was determined as follows: the ${ }^{125}$ I counts per minute of the erythrocyte fractions of the blood entering and leaving the given organ were plotted as a function of time. The time course of IC removal from the erythrocyte fraction was divided into an early phase $(0-5 \mathrm{~min})$ and a late phase $(5-30 \mathrm{~min}) .5 \mathrm{~min}$ was chosen as the dividing line since the period of $0-5 \mathrm{~min}$ corresponded to the period of the greatest rate of removal of IC from the blood (Results). The area under the early phase curve of the ${ }^{125}$ I counts per minute on erythrocytes entering (A) and leaving (B) the given organ was then determined. The fraction of the ${ }^{125}$ I-labeled IC removed during the early phase was then calculated as $(\mathrm{A}-\mathrm{B}) / \mathrm{A}$. The late phase fractional removal of IC from erythrocytes was calculated as the ratio: 1 - (mean ${ }^{125} \mathrm{I} \mathrm{cpm}$ on erythrocytes leaving the organ at the 5,15 , and $30 \mathrm{~min}$ time points)/(mean ${ }^{125} \mathrm{I} \mathrm{cpm}$ on erythrocytes entering the given organ at the 5,15 , and $30 \mathrm{~min}$ time points). This simpler formula was used for the late phase calculation because, in general, the late phase values represented low and nearly steady-state values with only small differences between the ${ }^{125} I$ counts per minute on the erythrocytes entering and leaving the given organ.

The IC on erythrocytes entering and leaving the kidney were taken as the ${ }^{125} I$ counts per minute in the erythrocyte fractions of the arterial and renal venous blood samples, respectively. The IC on erythrocytes entering and leaving spleen + gut were taken as the ${ }^{125}$ I counts per minute in the erythrocyte fractions of the arterial and portal venous blood samples, respectively. To determine the IC on erythrocytes entering liver (via hepatic artery and portal vein), the following corrections were applied to the ${ }^{125}$ I counts per minute in the erythrocyte fraction of each hepatic artery and portal 


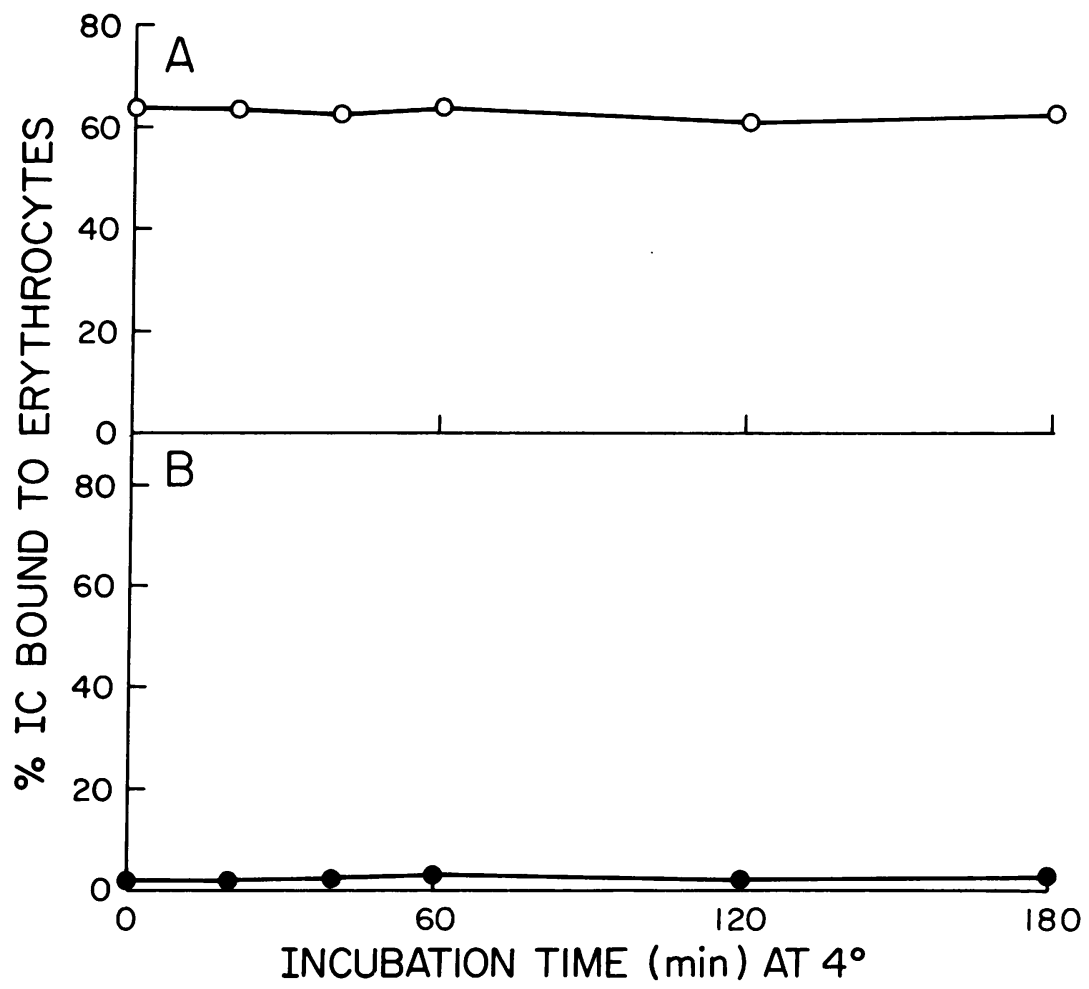

FIGURE 1 Absence of IC binding to or dissociation from erythrocytes at $4^{\circ} \mathrm{C}$. In one experiment (panel A), equal volumes of IC, fresh baboon plasma (10 U heparin $/ \mathrm{ml}$ ), and packed baboon erythrocytes were mixed together in a series of tubes and placed at $37^{\circ} \mathrm{C}$ for $10 \mathrm{~min}$, and then at $4^{\circ} \mathrm{C}$ thereafter. In another experiment (panel B), equal volumes of $\mathrm{IC}$, fresh baboon plasma, and baboon erythrocytes were mixed together in a series of tubes and incubated from the outset at $4^{\circ} \mathrm{C}$. At $0,20,40,60,120$, and $180 \mathrm{~min}$ duplicate tubes were removed and the reaction mixtures were placed on iced percoll for separation of erythrocyte-bound IC from unbound IC. For each experiment, mean percent IC bound to erythrocytes was plotted against incubation time at $4^{\circ} \mathrm{C}$

vein blood specimen. In the experiments in which microspheres were not used, the relative contribution of hepatic artery and portal vein blood flow to total hepatic blood flow was apportioned as follows: $0.32\left({ }^{125} \mathrm{I} \mathrm{cpm}\right.$ in the arterial blood erythrocyte fraction) +0.68 ( ${ }^{125} \mathrm{I} \mathrm{cpm}$ in the portal vein erythrocyte fraction). This apportionment of total hepatic flow into hepatic artery and portal vein flow is based on our previously reported studies in dogs, using the microsphere method (described below) to determine hepatic artery and portal vein blood flow (11). In the 24 experiments in dogs, hepatic artery flow averaged $32 \%$ (range 5 to $60 \%$ ) of total hepatic blood flow. It should be noted that the wide variation between values of individual experiments is inherent in this method. In the three experiments in primates in which microspheres were infused, the actual distribution of the microspheres was used to determine the relative contribution of hepatic artery and portal vein blood flow to total hepatic blood flow. The data in these three experiments were in general agreement with the data obtained in the dog. That is, hepatic artery flow in the three primate experiments was $46.2,40.1$, and $8.6 \%$ of total liver blood flow, for a mean value of $31.6 \%$. The IC on erythrocytes leaving liver were taken as ${ }^{125}$ I counts per minute in the erythrocyte fraction of the hepatic vein blood samples.
Fractional removal of IC from the nonerythrocyte fraction of blood (plasma/buffy coat fraction). To determine the extent to which IC were removed from the blood by mechanisms other than the erythrocyte-IC-clearing mechanism, the ${ }^{125}$ I content of the entire percoll fraction of each blood specimen was measured and plotted vs. time. These data were then analyzed exactly as was done for the erythrocyte fractions of blood, as discussed above. The percoll fractions contained ${ }^{125} \mathrm{I}$-labeled IC free in the plasma, ${ }^{125} \mathrm{I}-$ labeled IC bound to leukocytes and platelets, and the ${ }^{125} \mathrm{I}$ BSA free in the plasma. Hereafter, this fraction of blood will be referred to as the plasma/buffy coat fraction.

Fraction of total hepatic blood flow via the hepatic artery. This fraction was taken as the ratio: (total microsphere cpm in liver)/(total microsphere cpm in liver + spleen + stomach + large bowel + small bowel + pancreas). The rationale for this calculation is that the microspheres in liver represent hepatic artery blood flow, while the microspheres in spleen + gut + pancreas represent blood flow to the liver via the portal vein (11)

Fraction of total hepatic blood flow via the portal vein. This fraction was calculated as ( 1 - the fraction of hepatic blood flow via the hepatic artery).

Tissue vascular volume. The fraction of tissue volume 
that represented blood volume was taken as the ratio: $\left({ }^{51} \mathrm{Cr}\right.$ $\mathrm{cpm} / \mathrm{g}$ of given tissue $) /\left({ }^{51} \mathrm{Cr} \mathrm{cpm} / \mathrm{ml}\right.$ whole blood) (11).

Vascular space correction. To determine the extent to which the tissue ${ }^{125}$ I counts represent ${ }^{125}$ I-labeled IC actually deposited in tissues vs. ${ }^{125}$ I-labeled material, which is simply passively retained in the vascular space at the time the tissues were excised, a correction factor based on the ${ }^{51} \mathrm{Cr}$ counts in the vascular space and ${ }^{125} \mathrm{I}$ counts in whole blood was applied as follows: ${ }^{125} \mathrm{I} \mathrm{cpm}$ deposited in tissue $={ }^{125} \mathrm{I} \mathrm{cpm} /$ $\mathrm{g}$ of tissue $-\left({ }^{51} \mathrm{Cr} \mathrm{cpm} / \mathrm{g}\right.$ of tissue $) \times\left({ }^{125} \mathrm{I} \mathrm{cpm} / \mathrm{g}\right.$ of whole blood) $/\left({ }^{51} \mathrm{Cr} \mathrm{cpm} / \mathrm{ml}\right.$ of whole blood), as described previously (14).

Hemodynamic data. Mean systolic blood pressure at the start of the experiment was $82 \pm 6 \mathrm{mmHg}$ and was stable during the experiment. Mean hematocrit at the start of the experiment was $33 \pm 4 \%$ and decreased by $\sim 5 \%$ during the experiment due to the volume of blood samples removed and saline infused. In no instance was hemolysis noted.

\section{RESULTS}

\section{Clearance of preformed IC}

The results of a representative experiment are shown in Figs. 2 and 3. As can be seen from comparison of the ${ }^{125} I$ counts per minute in the arterial blood erythrocyte fraction (Fig. 2) to the ${ }^{125} I$ counts per minute in the arterial blood plasma/buffy coat fraction (Fig. $3)$, the majority of the ${ }^{125}$ I-labeled IC infused into the arterial blood become bound to erythrocytes. Furthermore, as the IC-bearing erythrocytes traverse liver the great majority of their IC burden is deposited. This is shown in Fig. 2 by the low ${ }^{125} I$ counts per minute in the erythrocytes exiting liver (hepatic vein erythrocyte fraction) compared with the high ${ }^{125} \mathrm{I}$ counts per minute on erythrocytes entering liver (hepatic artery + portal vein erythrocyte fractions). The erythrocytes themselves were not trapped in liver, as shown in Fig. 4. ${ }^{51} \mathrm{Cr}$-Labeled erythrocytes bind IC in vitro to the same extent as do erythrocytes not subjected to the process of ${ }^{51} \mathrm{Cr}$-labeling (Fig. 5). Thus, under these conditions, the behavior of the ${ }^{51} \mathrm{Cr}$-labeled erythrocytes is representative of the general erythrocyte population.

The spleen appears to function in the same manner as the liver as shown by the fact that the ${ }^{125} \mathrm{I}$-labeled IC are efficiently removed from the erythrocytes traversing the organs served by the portal vein (spleen + gut) and, as shown below, most of the IC deposited in spleen + gut are deposited in spleen. The ${ }^{51} \mathrm{Cr}$-labeled erythrocytes are not detained by the spleen.

The handling of IC-bearing erythrocytes by kidney stands in striking contrast to that of the liver. By comparing the ${ }^{125} \mathrm{I}$ counts per minute in arterial blood to that of renal vein, it is evident that the IC-bearing erythrocytes exit kidney with IC burden virtually intact (Fig. 2).

The handling of the plasma/buffy coat fraction of blood by liver, kidney, and spleen + gut is shown in

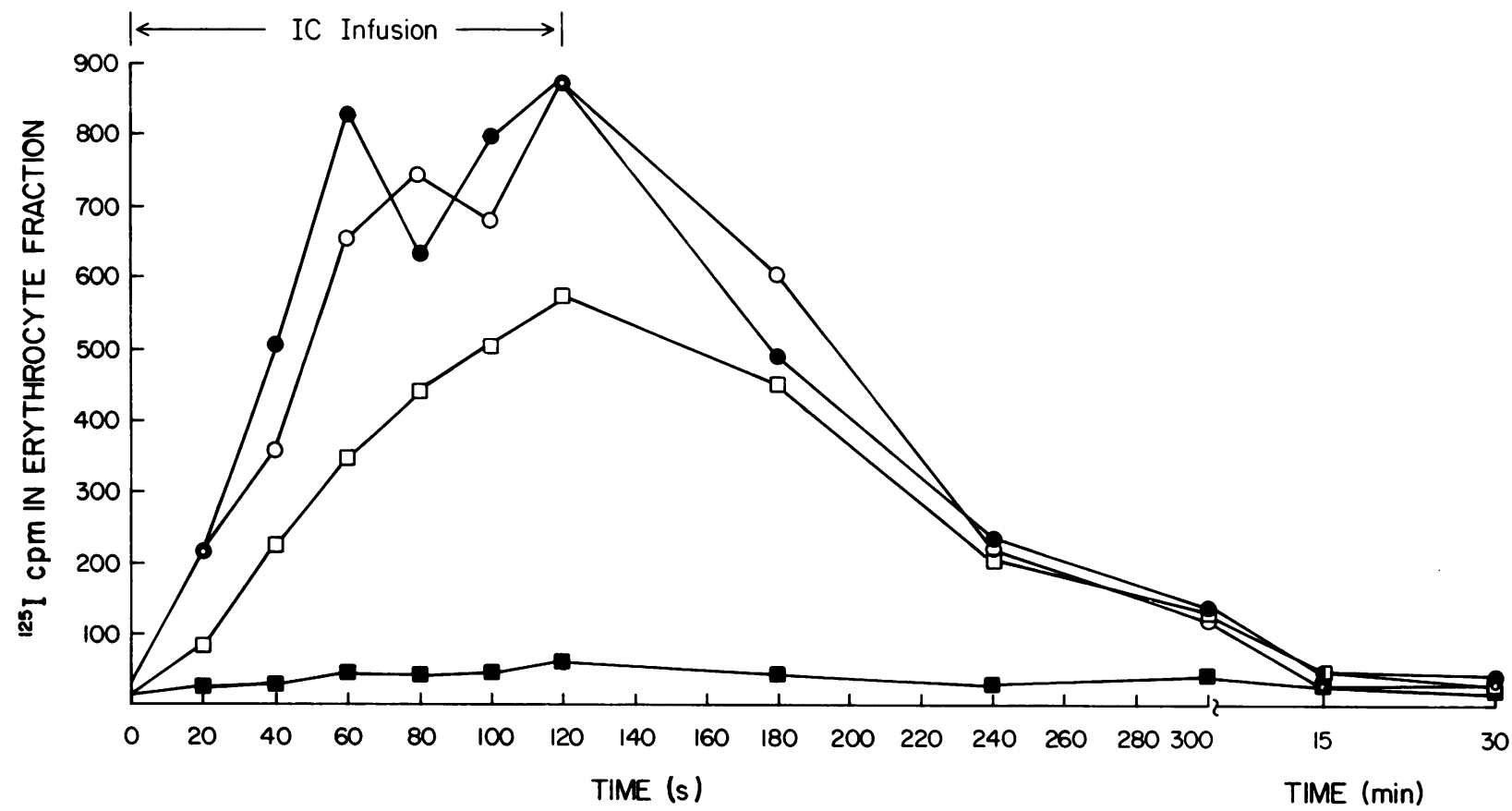

Figure 2 Representative study. Sequential changes in ${ }^{125}$ I counts per minute in erythrocyte fractions of blood samples drawn simultaneously from arterial $(\bullet)$, renal vein $(O)$, portal vein (ם) and hepatic vein ( $\square$ ) catheters before, during, and after infusion of ${ }^{125} \mathrm{I}$-labeled IC. 


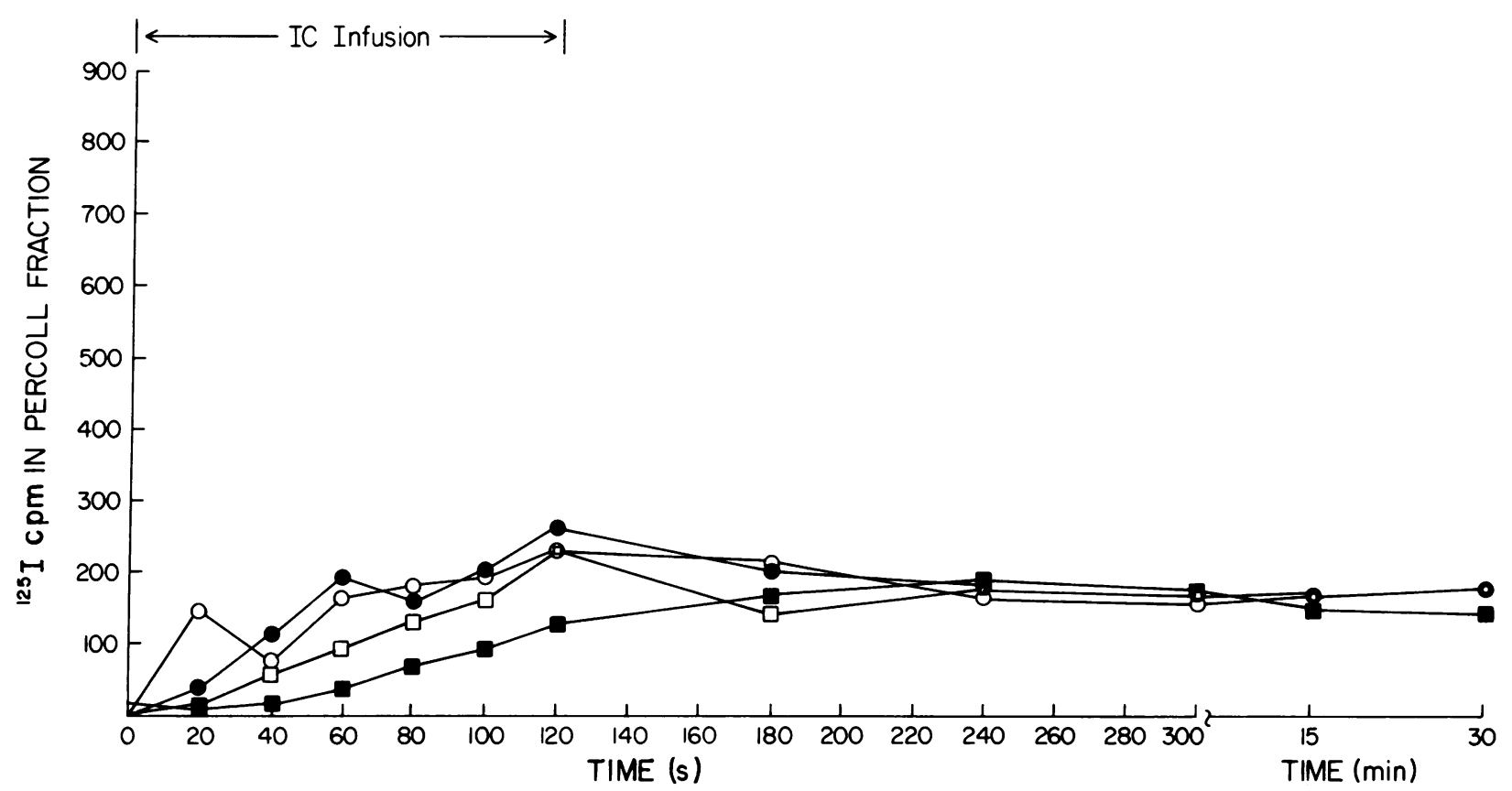

FIGURE 3 Representative study. Sequential change in ${ }^{125} \mathrm{I}$ counts per minute in percoll fractions of blood samples obtained from arterial $(\bullet)$, renal vein $(O)$, portal vein $(\square)$, and hepatic vein (D) catheters as in the experiment depicted in Fig. 1. Percoll fraction refers to the plasma/ buffy coat fraction.

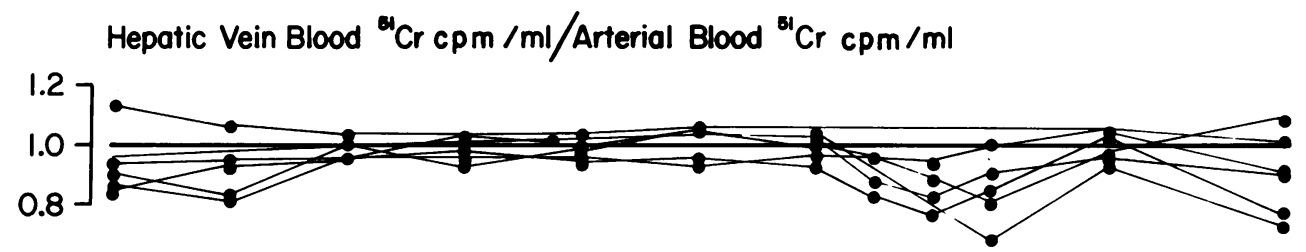

Renal Vein Blood ${ }^{B 1} \mathrm{Cr} \mathrm{cpm} / \mathrm{ml} /$ Arterial Blood ${ }^{51} \mathrm{Cr} \mathrm{cpm} / \mathrm{ml}$

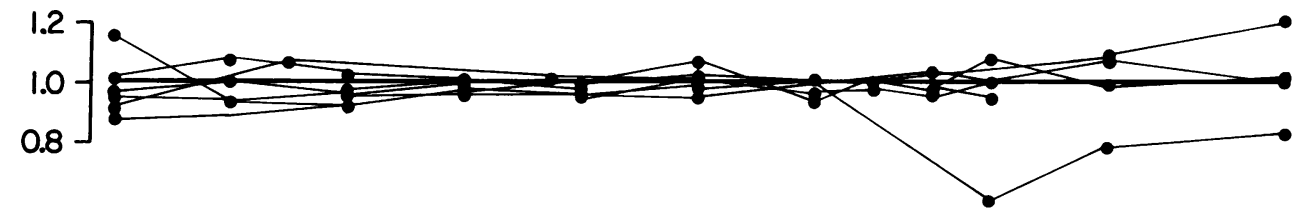

Portal Vein Blood ${ }^{81} \mathrm{Cr} \mathrm{cpm} / \mathrm{ml} /$ Arterial Blood ${ }^{51} \mathrm{Cr} \mathrm{cpm} / \mathrm{ml}$

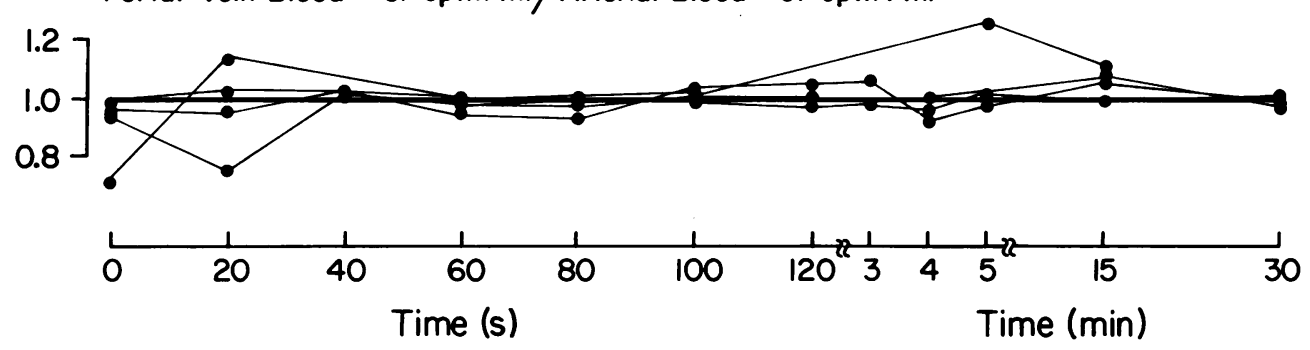

Figure 4 Fractional removal of ${ }^{51} \mathrm{Cr}$-labeled erythrocytes traversing liver, kidney, or spleen + gut, before, during, and after infusion of IC over the time period from 0 to $120 \mathrm{~s}$. The fractional rate of removal of ${ }^{51} \mathrm{Cr}$-labeled erythrocytes by the respective organ systems was estimated from the ratios shown above each graph. 


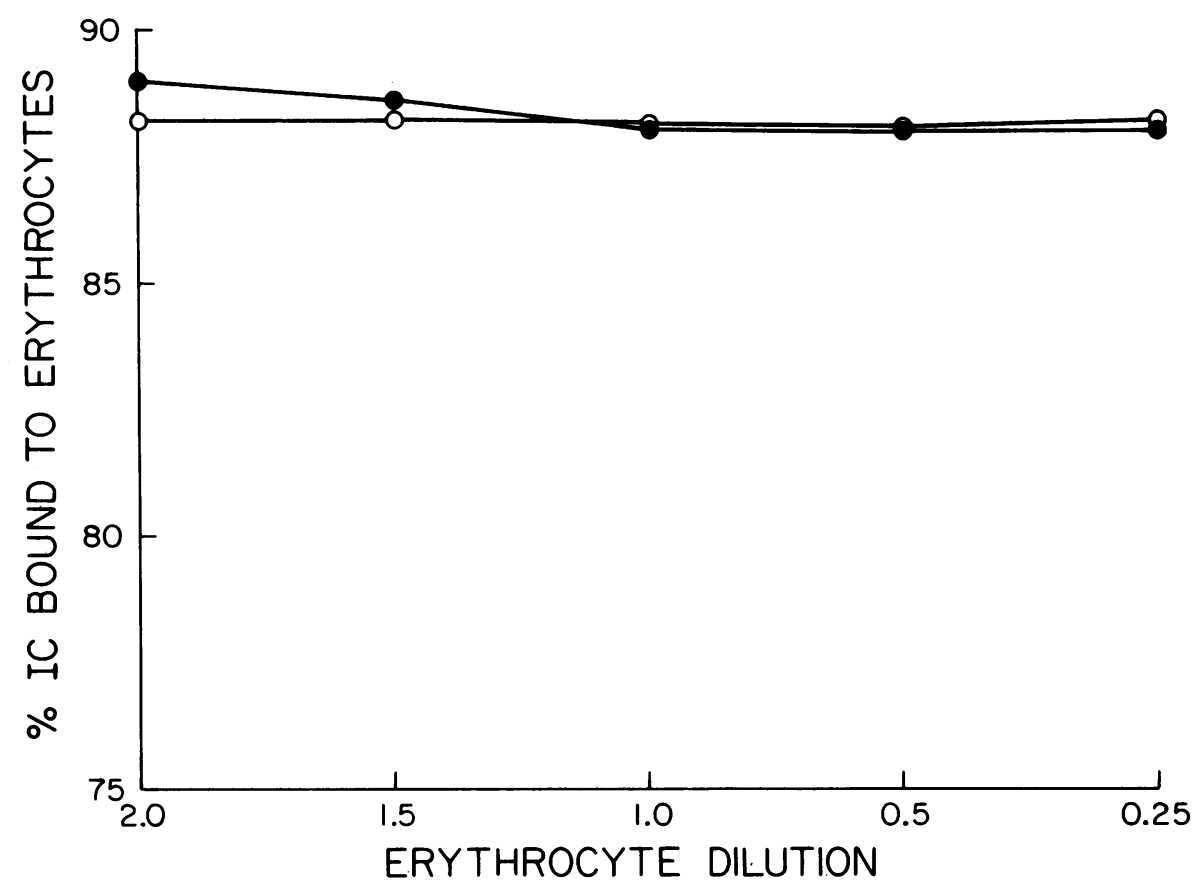

Figure 5 Binding of IC by ${ }^{51} \mathrm{Cr}$-labeled vs. unlabeled erythrocytes. Baboon erythrocytes were obtained in $15 \%$ acid citrate dextrose solution and washed twice in PBS. A portion was removed and labeled with ${ }^{51} \mathrm{Cr}$. $50 \mu \mathrm{l}$ of IC was added to $50 \mu \mathrm{l}$ of fresh baboon serum in a series of tubes. In one set of tubes, varying quantities of packed ${ }^{51} \mathrm{Cr}$-labeled erythrocytes were added as follows: $100 \mu$ l (2.0 dilution), $75 \mu$ l (1.5 dilution), $50 \mu$ l (1.0 dilution), $25 \mu$ l (0.5 dilution), and $12.5 \mu \mathrm{l}(0.25$ dilution). In another set of tubes, packed unlabeled erythrocytes were added in the same dilutions. All reaction mixtures were brought to a total of $200 \mu$ l with PBS. The tubes were incubated at $37^{\circ} \mathrm{C}$ for $10 \mathrm{~min}$, and the erythrocyte-bound IC were separated from the unbound IC by centrifugation on percoll. The mean percent IC bound to erythrocytes was plotted as a function of erythrocyte dilution for the ${ }^{51} \mathrm{Cr}$-labeled erythrocytes $(O)$ and the unlabeled erythrocytes $(\bullet)$.

Fig. 3. As can be seen, the ${ }^{125} \mathrm{I}$-labeled material in the plasma/buffy coat fractions is cleared at a minimal rate by liver and spleen + gut and not at all by kidney. Thus, IC free in the plasma phase or bound to leukocytes or platelets are cleared far less efficiently from the blood than are the IC bound to erythrocytes.

The IC clearance data from all seven experiments are summarized in Tables I and II. As can be seen from Table I, at 60-180 s the majority of the IC in blood were bound to erythrocytes. There was no correlation between the dose of IC administered and the observed level of IC binding to erythrocytes. However, by the end of the early phase $(5 \mathrm{~min})$ most $(73.1 \%)$ of the IC had been removed from the erythrocytes. In contrast, at this point only $17 \%$ of the ${ }^{125}$ I counts per minute in the plasma/buffy coat fraction had been removed. By 15 and $30 \mathrm{~min}$, a substantial increase was seen in the calculated fractional removal of IC from the plasma/buffy coat fraction. This, however, overestimates the actual fractional removal of IC since some of the loss of ${ }^{125} \mathrm{I}$-labeled material from the plasma/buffy coat fraction represents diffusion of free ${ }^{125} \mathrm{I}-\mathrm{BSA}$ into the interstitial space.
Table II shows the early phase clearance of IC by liver, kidney, and spleen + gut. As in the representative experiment (Figs. 2 and 3 ), there were high rates of IC clearance from the erythrocyte fraction by liver, no significant clearance by kidney, and intermediate rates of clearance by spleen + gut. Low but significant rates of IC clearance from the plasma/buffy coat fraction was observed for liver and spleen + gut.

The mean late phase clearance of IC from the erythrocyte fraction for all experiments was liver $50.1 \pm 8.4 \%$, kidney $-3.4 \pm 16 \%$, and spleen + gut $9.2 \pm 30 \%$, the mean value for liver was significantly $>0, P<0.001$. The mean values for kidney and spleen + gut were not significantly different from 0 . The mean late phase clearance of ${ }^{125} \mathrm{I}$-labeled material from the plasma/ buffy coat fraction of blood was liver $7.7 \pm 10 \%$, kidney $8.5 \pm 12 \%$, and spleen + gut $2.4 \pm 6 \%$. None of these mean values is significantly different from 0 . Thus, for the late phase data, only the hepatic removal of IC from the erythrocyte fraction showed values for fractional removal significantly different from 0 . It should be noted, however, that the rate of fractional removal of IC from the erythrocyte fraction by liver during the 
TABLE I

Binding of IC to Erythrocytes and their Subsequent Removal from the Erythrocyte Fraction and Plasma/Buffy Coat Fraction of Blood

\begin{tabular}{|c|c|c|c|c|c|c|c|c|c|}
\hline \multirow{3}{*}{$\begin{array}{l}\text { Exp } \\
\text { no. }\end{array}$} & \multicolumn{3}{|c|}{ Early phese (0-5 min) } & \multicolumn{6}{|c|}{ Late phase $(5-30 \mathrm{~min})$} \\
\hline & \multirow{2}{*}{$\begin{array}{l}\text { •IC bound to } \\
\text { erythrocytes } \\
\text { (Peak value) }\end{array}$} & \multirow{2}{*}{$\begin{array}{c}\text { IIC in } \\
\text { plasma/buffy } \\
\text { coat fraction } \\
\text { (Peak value) }\end{array}$} & \multirow{2}{*}{$\begin{array}{l}\text { Time of peak } \\
\text { value }\end{array}$} & \multicolumn{3}{|c|}{$\begin{array}{l}\text { Percent reduction in IC from peak } \\
\text { value of erythrocyte fraction }\end{array}$} & \multicolumn{3}{|c|}{$\begin{array}{l}\text { Percent reduction in IC from } \\
\text { peak value of plasma/buffy coat fraction }\end{array}$} \\
\hline & & & & $5 \mathrm{~min}$ & $15 \mathrm{~min}$ & $30 \mathrm{~min}$ & $5 \mathrm{~min}$ & $15 \mathrm{~min}$ & $30 \mathrm{~min}$ \\
\hline & \multicolumn{2}{|c|}{ \% } & 8 & & & & & & \\
\hline $1 \S$ & 85.3 & 14.7 & 120 & 83.7 & 94.5 & 95.3 & 36.4 & 34.8 & 34.5 \\
\hline 2 & 78.3 & 21.7 & 60 & 84.4 & 96.8 & 96.8 & 12.2 & 29.4 & 43.1 \\
\hline 3 & 47.6 & 52.4 & 180 & 39.3 & 70.2 & 34.0 & 3.6 & 17.0 & 18.8 \\
\hline 4 & 55.4 & 44.6 & 60 & 93.4 & 90.8 & 96.6 & 45.3 & 56.3 & 47.1 \\
\hline 5 & 17.7 & 82.3 & 120 & 85.8 & 92.6 & 81.7 & 18.5 & 40.9 & 46.9 \\
\hline 6 & 69.7 & 30.3 & 80 & 59.1 & 93.6 & 97.1 & -18.6 & 34.7 & 42.4 \\
\hline 7 & 74.6 & 25.4 & 120 & 65.8 & 79.2 & 96.8 & 21.7 & 24.6 & 28.1 \\
\hline \multirow[t]{4}{*}{ Mean } & $61.2 \pm 8.8$ & $38.8 \pm 8.8$ & \multirow{3}{*}{ "Mean $\mathbf{Q}_{\mathbf{E}}$} & $73.1 \pm 7.2$ & $88.2 \pm 3.7$ & $90.8 \pm 3.9$ & $17.0 \pm 8.0$ & $34.0 \pm 4.7$ & $37.3 \pm 4.0$ \\
\hline & & & & $5 \mathrm{~min}$ & $15 \mathrm{~min}$ & $30 \mathrm{~min}$ & & & \\
\hline & & & & $44.8 \pm 8.2$ & $54.4 \pm 8.7$ & $57.0 \pm 9.3$ & & & \\
\hline & & & IMean $Q_{P}$ & $6.5 \pm 3.3$ & $13.7 \pm 4.2$ & $14.8 \pm 4.4$ & & & \\
\hline
\end{tabular}

- As defined in Methods.

$\downarrow$ Percent IC in plasma/buffy coat fraction (peak value) $=100 \%-\%$ IC bound to erythrocytes (peak value).

$\$$ Experiment 1 is the representative study shown in Figs. 2 and 3.

" $Q_{E}$ (percent of peak IC load removed from blood by erythrocyte fraction) $=\%$ IC bound to erythrocytes (peak value) $\times \%$ reduction of $I C$ in erythrocyte fraction at time $t$, where $t=5,15$, or $30 \mathrm{~min}$. The mean value shown is the average of the individual experiments. I $Q_{P}$ (percent of peak IC load removed from blood by plasma/buffy coat fraction) $=\%$ IC in plasma/buffy coat fraction (peak value) $X \%$ reduction of IC in percoll fraction at time $t$, where $t=5,15$, or $30 \mathrm{~min}$. The mean value shown is the average of the individual experiments.

late phase was much lower than that observed during the early phase (late phase: $50.1 \% / 25 \mathrm{~min}=2.0 \%$ / $\mathrm{min}$ ) vs. (early phase: $73.1 \% / 5 \mathrm{~min}=14.6 \% / \mathrm{min}$ ).

\section{Tissue analysis}

The following data were taken from the three experiments $(1,2$, and 5$)$ in which the animals were

TABLE II

Early Phase (0-5 min) Data on the Removal of IC from the Erythrocyte Fraction and the Plasma/Buffy Coat (Percoll)

Fraction of Blood by Liver, Kidney, and Spleen + Gut

\begin{tabular}{|c|c|c|c|c|c|c|}
\hline \multirow[b]{2}{*}{$\begin{array}{l}\text { Experiment } \\
\text { no. }\end{array}$} & \multicolumn{2}{|c|}{ Liver } & \multicolumn{2}{|c|}{ Kidney } & \multicolumn{2}{|c|}{ Spleen + Gut } \\
\hline & $\begin{array}{l}\text {-IC: removed from } \\
\text { erythrocyte } \\
\text { fraction }\end{array}$ & $\begin{array}{l}{ }^{128} \text { I-labeled material } \\
\text { removed from } \\
\text { percoll fraction }\end{array}$ & $\begin{array}{l}\text { IC removed from } \\
\text { erythrocyte } \\
\text { fraction }\end{array}$ & $\begin{array}{l}\text { 1251-Labeled material } \\
\text { removed from } \\
\text { percoll fraction }\end{array}$ & $\begin{array}{l}\text { IC removed from } \\
\text { erythrocyte } \\
\text { fraction }\end{array}$ & $\begin{array}{l}\text { 125I-Labeled material } \\
\text { removed from } \\
\text { percoll fraction }\end{array}$ \\
\hline & \multicolumn{2}{|c|}{$\%$} & \multicolumn{2}{|c|}{$\%$} & \multicolumn{2}{|c|}{$\%$} \\
\hline $1 \ddagger$ & 84.8 & 23.4 & 2.5 & 0.8 & 30.0 & 18.3 \\
\hline 2 & 59.6 & -1.0 & -0.8 & 11.3 & 28.1 & 24.3 \\
\hline 3 & 47.4 & 32.5 & -15.4 & 16.9 & 11.6 & 16.9 \\
\hline 4 & 75.7 & 20.7 & 23.5 & 12.9 & 40.7 & 16.4 \\
\hline $5 \S$ & 64.9 & 33.3 & 16.8 & 2.7 & - & - \\
\hline 6 & 92.0 & 14.6 & 6.3 & -5.4 & 21.1 & -2.6 \\
\hline $7 \S$ & 60.5 & 52.9 & -2.5 & -11.8 & - & - \\
\hline Mean & $69.3 \pm 5.9$ & $25.2 \pm 6.4$ & $4.3 \pm 4.9$ & $3.9 \pm 3.9$ & $26.3 \pm 4.8$ & $14.7 \pm 4.5$ \\
\hline
\end{tabular}

- As defined in Methods.

$\downarrow$ Experiment 1 is the representative study shown in Figs. 2 and 3.

$\$$ Portal vein blood samples were not taken in these experiments. The hepatic fractional removal of IC and ${ }^{125}$ I-labeled material was calculated using the values for arterial and hepatic vein blood samples. 
killed immediately after the conclusion of the experimental protocol. The results of the individual experiments are given in the following sequence: experiment 1 , then 2 , then 5 .

Tissue uptake of IC. The total ${ }^{125}$ I counts per minute injected into each animal varied. Thus, to permit comparison between experiments, the tissue uptake of ${ }^{125} \mathrm{I}$, after correction for vascular space ${ }^{125} \mathrm{I}$ (Methods), is expressed as the ratio: ( ${ }^{125} \mathrm{I} \mathrm{cpm} / \mathrm{g}$ of a given organ)/ ( ${ }^{125} \mathrm{I} \mathrm{cpm} / \mathrm{g}$ of liver).

The following ratios were obtained: kidney (cortex)/ liver: $0.012,0.000,0.000$; spleen/liver: 1.99, 0.48, 0.76; lung/liver: 0.28 , not done in No. 2, 0.88; gut (mean of stomach + large bowel + small bowel + pancreas)/ liver $0.030,0.01,0.038$. In these three experiments, the percent of total ${ }^{125}$ I counts per minute infused which were deposited in the various organs was liver $67,32.8,26.1$; spleen $6.8,0.7,1.2$; kidney $0.03,0.00$, 0.00 ; gut $0.4,0.13,0.5$; and lung 7.9 , not done in No. $2,9.2$. The tissue analysis data show that the liver traps by far the greatest amount of the IC. Lung is also a significant site of deposition. Kidney and gut trap relatively small amounts of IC.

Tissue vascular volume. The tissue vascular volume was calculated from the ${ }^{51} \mathrm{Cr}$ in tissue and blood', as discussed in Methods. The values are as follows: liver $0.23,0.23,0.24$; lung 0.34 , not done in No. 2, 0.23; kidney $0.23,0.19,0.14$; spleen $0.35,0.50,0.65$. The calculated volumes were comparable to those we found in dog under similar conditions (11). Thus, there is no evidence of selective removal of ${ }^{51} \mathrm{Cr}$-labeled erythrocytes from the circulation. If this had occurred, even in a subtle fashion, the calculated tissue vascular allowance would have been inappropriately high (10).

\section{Isokinetic sucrose density gradient analysis of IC}

To determine the size of the IC used in these experiments and the size of IC which bind to erythrocytes, in vitro experiments were performed using erythrocyte suspensions depleted of buffy coat cells before incubation with IC. These experiments are depicted and described in Fig. 6. As can be seen, IC ranging in size from $10,000 \mathrm{~S}$ to $>288,000 \mathrm{~S}$ are present in the original IC preparation and this range of IC sizes was only slightly affected by incubation in fresh serum. The entire range of IC bound to erythrocytes. However, the percent of IC bound to erythrocytes increased markedly with increasing IC size.

\section{Search for evidence of the erythrocyte- IC-clearing mechanism under conditions in which IC can form in vivo}

Two additional experiments were performed to determine whether the operation of the erythrocyte-IC- clearing mechanism could be detected when IC are allowed to form in vivo by infusing antigen and antibody separately into the same animal. In one experiment antigen was infused first, followed 15 min later by antiserum. In the other experiment, the order of infusion was reversed. The proportion of antigen and antibody was that which approximated equivalence. In all other respects the protocol was the same as described in Methods. In both experiments $<4 \%$ of the ${ }^{125}$ I counts per minute were found in the erythrocyte fraction. On the basis of the experiment in which ${ }^{125} \mathrm{I}$ BSA was infused first, it could be determined that this small amount of erythrocyte-associated ${ }^{125} I$ could be attributed to nonspecific binding. Throughout both experiments whole blood ${ }^{125}$ I counts per minute fell gradually, after the BSA infusion was completed, probably largely reflecting the diffusion of ${ }^{125} \mathrm{I}-\mathrm{BSA}$ into the interstitial spaces. There was negligible removal of ${ }^{125}$ I-labeled material from either the erythrocyte or plasma/buffy coat fractions traversing liver or kidney. Thus, the erythrocyte-IC-clearing mechanism, or any other IC-clearing mechanism, was not detected in either of these experiments. Although negative, these experiments are useful since they show that specific hepatic removal of albumin ( $\left.{ }^{125} \mathrm{I}-\mathrm{BSA}\right)$ from the circulation (15) cannot explain the high rate of hepatic removal from the circulation of the preformed IC used in this study. These experiments also suggest that future studies to elucidate the operation of the erythrocyte-IC-clearing mechanism will require the use of specific populations of preformed IC since the percent binding to erythrocytes of IC forming in vivo appears to be very low.

\section{DISCUSSION}

This study demonstrates that when large, complementfixing IC are infused into the blood stream of primates, the great majority of these IC rapidly become bound to circulating erythrocytes. The mechanism of adherance of IC to erythrocytes in vivo is currently under investigation in our laboratory. However, in vitro, it has been shown that the binding of IC to primate erythrocytes is complement dependent (6-9). It is generally thought that $\mathrm{C} 3 \mathrm{~b}$ sites are generated on the IC, which then allow the IC to bind to erythrocyte $\mathrm{CR}_{1}$ receptors. C3b sites on IC are generated very rapidly. For example, previous studies have shown that, in vivo, C3b sites are generated on IgM-sensitized erythrocytes so rapidly that only liver blood flow limits the rate at which the sensitized erythrocytes are removed from the circulation by the $\mathrm{C} 3 \mathrm{~b}$ receptors of the hepatic mononuclear phagocyte system (16). It has also been shown that C3b-mediated binding of preformed IC to leukocytes in vivo can be detected within $30 \mathrm{~s}$ of in- 


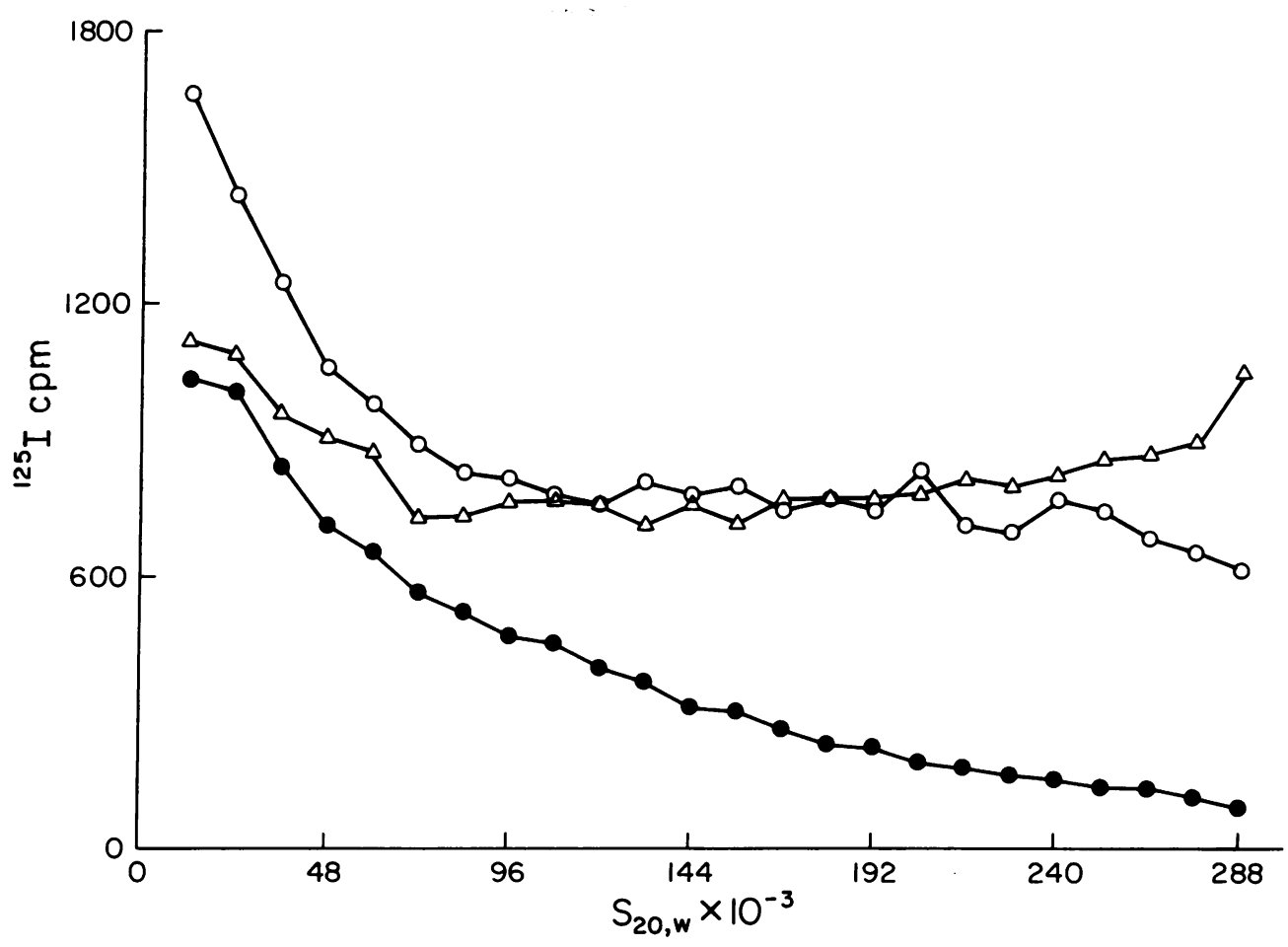

FIGURE 6 Isokinetic sucrose gradient analysis of IC. Equal volumes of IC + fresh baboon serum + packed baboon erythrocytes $(\Theta)$, IC + fresh baboon serum + PBS (O), and IC + heat-inactivated serum + packed baboon erythrocytes $(\Delta)$ were incubated at $37^{\circ} \mathrm{C}$ for $10 \mathrm{~min}$. Each reaction mixture was centrifuged on percoll for separation of erythrocyte-bound IC from unbound IC. The surface of the percoll phase (unbound IC) from each reaction mixture was then centrifuged on isokinetic sucrose gradients and fractions were collected. The data are expressed as the ${ }^{125}$ I counts per minute in each fraction plotted against the corresponding sedimentation coefficient $\left(S_{20}, w\right)$ in Svedberg units. The relative size of IC bound by erythrocytes can be estimated by comparing the size of unbound IC in the experimental reaction mixture (๑) with the size of the corresponding IC in the two control groups $(O, \Delta)$. Less than $10 \%$ of the counts per minute in the IC preparations exceeded $288,000 \mathrm{~S}$.

fusion of the IC (17). Thus, the speed of binding of IC to erythrocytes observed in this study is consistent with the hypothesis that the binding reaction is complement mediated.

IC bound to erythrocytes do not cause detectable hemolysis in vitro (8) or in vivo. It is tempting to speculate that this lack of hemolysis is due to the inhibitory effect of the $\mathrm{CR}_{1}$ receptor on activation of the complement cascade $(18,19)$. Thus, the erythrocyte is not damaged by attachment to the IC. Indeed, in vitro studies have shown that if IC are cleaved from the erythrocyte by prolonged exposure to the complementdependent release activity of fresh serum (20), the erythrocyte is, once again, able to bind IC (21).

Although IC-bearing erythrocytes can be demonstrated to aggregate in vitro (immune adherence reaction [6]) there was no evidence in this study that the IC-bearing erythrocytes aggregate in vivo. If this had occurred, there should have been evidence of ${ }^{51} \mathrm{Cr}$ labeled erythrocytes being removed from the circu- lation as erythrocyte aggregates traversed liver, kidney, or spleen + gut. However, there were no ${ }^{51} \mathrm{Cr}$ gradients across these organs and calculated tissue vascular volumes were normal. It is possible that the shearing forces on erythrocytes in the circulation are greater than the immune adherence forces that aggregate IC-bearing erythrocytes in vitro. In any event, there was no evidence that binding of IC to erythrocytes in vivo resulted in detectable erythrocyte aggregation.

This study further demonstrates that, after the IC have become bound to the erythrocyte in vivo, the IC do not deposit in organs such as kidney or gut as the IC-bearing erythrocytes traverse these organs. Instead, the IC are efficiently removed from the erythrocyte as the IC-bearing erythrocyte traverses liver or spleen. The erythrocyte then exits liver or spleen apparently able, once again, to participate in this "erythrocyteIC-clearing mechanism."

The mechanism by which IC are removed from 
erythrocytes as they traverse liver is not known. It is possible that, as the first step, the exposed Fc regions of the IC bound to the erythrocyte attach themselves to the Fc receptors of the tissue-bound hepatic mononuclear phagocyte. There is evidence that binding of IC to macrophages via the $\mathrm{Fc}$ receptor results in ingestion of the IC (5). Thus, the fact that the IC removed from the erythrocytes traversing liver are not released back into the hepatic circulation suggests that the IC have been ingested by the hepatic macrophages. This would be in contrast to the hepatic uptake of IgMsensitized erythrocytes, which occurs via hepatic macrophage receptors for $\mathrm{C} 3 \mathrm{~b}$. In that situation the erythrocytes are released back into the circulation within $30 \mathrm{~min}$, probably through the enzymatic action of C3b inactivator (16). Although no evidence of release of IC back into the hepatic circulation was detected in the study presented here, the possibility that erythrocyte-bound IC bind to hepatic macrophages via both $\mathrm{C} 3 \mathrm{~b}$ and $\mathrm{Fc}$ receptors is not excluded.

If the first step in the hepatic uptake of erythrocytebound IC is the binding of the IC to hepatic macrophage C3b and/or Fc receptors, the second step is the breaking free of the erythrocyte from the macrophagebound IC. This could occur mechanically, because of the force of blood flow on the relatively rigid erythrocyte causes the erythrocyte to tear free from its attachment to the hepatic macrophage. If the total force binding the IC to the hepatic macrophage is greater than the total force binding the IC to the erythrocyte, the erythrocyte will break free leaving the IC bound to the hepatic macrophage. Alternatively, C3b inactivator or some other enzyme could cleave the bond between IC and erythrocytes. Indeed, Medof et al. (22) have shown that erythrocyte $\mathrm{CR}_{1}$ receptor markedly enhance the activity of C3b inactivator. Thus, it seems possible that a synergistic interaction between mechanical and enzymatic factors in liver could be responsible for the extremely efficient uptake of erythrocyte-bound IC by liver.

In contrast to the rapid hepatic removal of IC from the erythrocyte fraction of blood, the hepatic removal of IC from the plasma/buffy coat fraction of blood was considerably slower. This could reflect strong binding or phagocytosis of IC by peripheral blood leukocytes rendering the IC unavailable to the hepatic mononuclear phagocytes. It is also possible that the IC in the plasma phase represent a population of smaller IC that are cleared by the liver less efficiently than are larger IC $(23,24)$.

The preformed IC used as the biological probe in this study are much larger than are those used traditionally and were chosen simply because they showed the highest level of binding to primate erythrocytes in vitro. The biological significance of such large IC is not clear. However, Cameron (25) has recently provided arguments that the nephritogenic IC are large, insoluble or poorly soluble IC formed near equivalence, and not the small, soluble IC that circulate in plasma. It is possible, nevertheless, that such large circulating IC do not occur in pathophysiologic states and that the erythrocyte-IC-clearing mechanism is directed mainly at clearing less large IC at a less efficient rate than the very large preformed IC used in this study. Indeed, it is clear that, in vitro, smaller IC can bind to primate erythrocytes. Waller et al. (26) have demonstrated low level binding of preformed DNA anti-DNA IC to human erythrocytes when IC size is $<175 \mathrm{~S}$ but high level binding as IC size approaches $600 \mathrm{~S}$. Medof et al. (27) have shown that preformed BSA-anti-BSA IC smaller $(\sim 200 \mathrm{~S})$ than those used in the present study can bind to primate erythrocytes in vitro. However, high dilution of the complement source ( $1: 8$ to $1: 16$ dilution of serum) is needed for maximum binding of these smaller IC (9).

In this study, IC binding to erythrocytes was not detected in vivo when free antigen and antibody were infused separately. This, however, may simply indicate that IC of sufficient size to permit binding to erythrocytes form at a rate which is too low and/or are cleared too quickly to be detected under the present experimental conditions. Thus, studies to elucidate further the operation of the erythrocyte-IC-clearing mechanism will apparently also require the use of specific populations of preformed IC.

The erythrocyte-IC-clearing mechanism is, evidently, largely an adaptation of man and other primates. Lower forms of animals have some ability of their erythrocytes to bind to IC, possibly through Fc receptors (28) or antibody-aggregated $\mathrm{C} 4$ receptors (29). However, only primates have vast numbers of $\mathrm{CR}_{1}$ receptors on circulating erythrocytes. The present study demonstrates the existence in primates of a potentially important erythrocyte-IC-clearing mechanism and provides a teleologically satisfying explanation for the existence of the vast numbers of $\mathrm{CR}_{1}$ receptors on circulating erythrocytes. Failure or insufficiency of the erythrocyte-IC-clearing mechanism might increase the probability of deposition of IC in vulnerable organs, such as kidney, and concomitantly decrease the probability of safe disposal of IC in liver or spleen. Indeed, this may occur in patients with systemic lupus erythematosus who have deficient numbers of erythrocyte $C_{1}$ receptors $(3,30,31)$ or in whom the erythrocyte $\mathrm{CR}_{1}$ receptors are occupied by IC $(32,33)$. Thus, inadequacy of the erythrocyte-ICclearing mechanism could play an important role in the clinical expression of systemic lupus erythematosus and other diseases mediated by deposition of circulating IC. 


\section{ACKNOWLEDGMENTS}

We gratefully acknowledge the help of Dr. Ronald Taylor of the University of Virginia in setting up the technique of isokinetic sucrose gradient ultracentrifugation, and Carmela Price for her secretarial assistance.

This work was supported, in part, by National Institutes of Health grant HL25404 and a grant from the National Kidney Foundation of Central Ohio.

\section{REFERENCES}

1. Fearon, D. T. 1980. Identification of the membrane glycoprotein that is the $\mathrm{C} 3 \mathrm{~b}$ receptor of the human erythrocyte, polymorphonuclear leukocyte, B lymphocyte, and monocyte. J. Exp. Med. 152: 20-30.

2. Dobson, N. J., J. D. Lambris, and G. D. Ross. 1981. Characteristics of isolated erythrocyte complement receptor type one $\left(C_{1}, C 4 b-C 3 b\right.$ receptor) and $C_{1}$-specific antibodies. J. Immunol. 126: 693-698.

3. Iida, K., R. Mornaghi, and V. Nussenzweig. 1982. Complement receptor $\left(\mathrm{CR}_{1}\right)$ deficiency in erythrocytes from patients with systemic lupus erythematosus. J. Exp. Med. 155: 1427-1438.

4. Siegel, I., T. L. Liu, and N. Gleicher. 1981. The red-cell immune system. Lancet. II: 556-559.

5. Ehlenberger, A. G., and V. Nussenzweig. 1977. The role of membrane receptors for $\mathrm{C} 3 \mathrm{~b}$ and $\mathrm{C} 3 \mathrm{~d}$ in phagocytosis. J. Exp. Med. 145: 357-371.

6. Rothman, I. K., J. A. Gelfand, A. S. Fauci, and M. M. Frank. 1975. The immune adherence receptor: dissociation between the expression of erythrocyte and mononuclear cell C3b receptors. J. Immunol. 115: 1312-1315.

7. Aikawa, T., T. Mitamura, K. Tanimoto, and Y. Horiuchi. 1979. Detection of circulating immune complexes by using human red blood cells. J. Lab. Clin. Med. 94: 902916.

8. Cornacoff, J. B., R. A. Zager, and L. A. Hebert. 1981. Mechanism of binding of immune complexes to human erythrocytes. Clin. Res. 29: 364a. (Abstr.)

9. Medof, M. E., and J. J.-F. Oger. 1982. Competition for immune complexes by red cells in human blood. J. Clin. Lab. Immunol. 7: 7-13.

10. Hebert, L. A., K. A. Stuart, C. L. Allhiser, and G. E. Rodey. 1976. Measurement of the fractional uptake of macromolecules by the renal vascular bed compared to other vascular beds. J. Lab. Clin. Med. 88: 716-724.

11. Hebert, L. A., C. L. Allhiser, and S. M. Koethe. 1978. Some hemodynamic determinants of immune complex trapping by the kidney. Kidney Int. 14: 452-465.

12. Creighton, W. D., P. H. Lambert, and P. A. Miescher. 1973. Detection of antibodies and soluble antigen-antibody complexes by precipitation with polyethylene glycol. J. Immunol. 111: 1219-1227.

13. Johns, P., and D. R. Stanworth. 1976. A simple numerical method for the construction of isokinetic sucrose density gradients and their application to the characterization of immunoglobulin complexes. J. Immunol. Methods. 10: 231-252.

14. Hebert, L. A., C. L. Allhiser, S. M. Koethe, and G. E. Rodey. 1978. Uptake of immune complexes by renal glomeruli and renal non-glomerular tissue. J. Clin. Lab. Immunol. 1: 99-105.

15. Weisinger, R., J. Gollan, and R. Ockner. 1981. Receptor for albumin on the liver cell surface may mediate uptake of fatty acids and other albumin-bound substances. Science (Wash. DC). 211 : 1048-1051.

16. Frank, M. M., A. D. Schreiber, J. P. Atkinson, and
C. J. Jaffe. 1977. Pathophysiology of immune hemolytic anemia. Ann. Intern. Med. 87: 210-222.

17. Cochrane, C. G., and D. Hawkins. 1967. Studies on circulating immune complexes, III. Factors governing the ability of circulating complexes to localize in blood vessels. J. Exp. Med. 127: 137-154.

18. Iida, K., and V. Nussenzweig. 1981. Complement receptor is an inhibitor of the complement cascade. J. Exp. Med. 153: 1138-1150.

19. Gigli, I., and D. T. Fearon. 1981. Regulation of the classical pathway convertase of human complement by the C3b receptor of human erythrocytes. Fed. Proc. 40: 1172a. (Abstr.)

20. Medof, M. E., D. Scarborough, and G. Miller. 1981. Ability of complement to release systemic lupus erythematosus immune complexes from cell receptors. Clin. Exp. Immunol. 44: 416-425.

21. Medof, M. E., J. F. Oger, and G. M. Prince. 1981. Kinetics of immune complex blood cell interactions: competition for complexes by RBCs. American Rheumatology Society, Boston (Abstr.).

22. Medof, M. E., G. M. Prince, and C. Mold. 1982. Red blood cells (RBC) are required for cleavages of $\mathrm{C} 3 \mathrm{~b}$ in immune complexes (IC) by C3b inactivator (I) in human blood. Clin. Res. 30: 353a. (Abstr.)

23. Mannik, M., and R. A. H. Jimenez. 1979. The mononuclear phagocyte system in immune complex diseases. Immunopathology. 6th International Convocation in Immunology, Niagara Falls, NY. 212-216.

24. Finbloom, D. S., and P. H. Plotz. 1979. Studies of reticuloendothelial function in the mouse with model immune complexes, I. Serum clearance and tissue uptake in normal C3H mice. J. Immunol. 123: 1594-1599.

25. Cameron, J. S. 1982. Glomerulonephritis: current problems and understanding. J. Lab. Clin. Med. 99: 755-787.

26. Waller, S. J., R. P. Taylor, E. L. Wright, K. W. Morley, and M. Johns. 1981. DNA/anti-DNA complexes. Correlation of size and complement fixation. Arthritis Rheum. 24: 651-657.

27. Medof, M. E., G. M. Prince, and J. J. F. Oger. 1982. Kinetics of interaction of immune complexes with complement receptors on human blood cells: modification of complexes during interaction with red cells. Clin. Exp. Immunol. 48: In press.

28. Hajos, S. E., R. A. Margni, G. Perdignon, M. Manghi, and R. Olivera. 1978. Binding of immunoglobulins and immune complexes to erythrocytes of vertebrates. Immunochemistry. 15: 623-628.

29. Davies, K., A. B. Wilson, and R. R. A. Coombs. 1981. Interaction of antibody-aggregated $\mathrm{C} 4$ and guinea pig red cells: coagglutination phenomenon of Bordet and Gengou. Immunology. 43: 699-706.

30. Wilson, J. G., W. W. Wong, P. H. Schurr, and D. T. Fearon. 1982. Familial deficiency of erythrocyte (E) C3b receptors (C3bR) in systemic lupus erythematosus (SLE). Clin. Res. 30: 544a. (Abstr.)

31. Miyakawa, Y., A. Yamada, K. Kosaka, F. Tsuda, E. Kosugi, and M. Mayumi. 1981. Defective immune-adherence (C3b) receptor on erythrocytes from patients with systemic lupus erythematosus. Lancet. II: 493-497.

32. Inada, Y., M. Kamiyama, C. L. Hyman, and W. C. Clark. 1981. C3b receptor activity and osmotic fragility of erythrocytes from immune complex disease patients. American Rheumatological Association, Boston. (Abstr.)

33. Siegel, I., and N. Gleicher. 1981. Red cell immune adherence (RCIA): its application in cancer and autoimmune disease. Immunol. Commun. 10: 433-449. 